\title{
Towards an understanding of how policy making groups use indicators
}

\author{
BELL, Simon \\ Communications and Systems Department, MCT Faculty, Open University \\ Milton Keynes, MK7 6AA. \\ Telephone: +44 (0)1953604594 \\ Email: s.g.bell@open.ac.uk \\ MORSE, Stephen \\ Centre for Environmental Strategy, University of Surrey \\ Guildford, Surrey GU2 7XH \\ Telephone: +44 (0) 1483686079 \\ Fax: +44 (0) 1483686671 \\ Email: s.morse@surrey.ac.uk
}

\begin{abstract}
Groupthink is a known weakness leading to a number of problems relating primarily to false senses of consensus. But, positive group 'wisdom' is an ideal which many aspire to make happen but few manage to achieve in practice. The mystery of the group comes at a number of levels and raises various questions such as: How to get people to assemble? How is the group motivated? What is the inducement? How do groups work? How can group work be assessed and how is a 'good' group identified? How is positive and not negative group working achieved? How is group working linked to what the group achieves? In the area of policy use of indicators the function of the group becomes more critical. In an age of transparency in decision making and calls for more evidence-based policy, the importance of good group work is becoming vital if the project is to succeed. Based on research undertaken around the European Union between 2009 and 2010 this paper explores some of these questions by providing a series of 'rich pictures' of indicator use, the meanings ascribed to the pictures by the group members and some insights regarding the dynamics of the groups that rest behind them and how this may have influenced the stories told by the pictures. We argue that in many ways the pictures become the windows to the understanding of the groups use of indicators.
\end{abstract}

Key words:

Rich picture, group work, policy, indicators 


\section{Introduction}

Indicators and indices (where an index comprises a number of indicators; for the sake of brevity these are herein referred to generically as indicators) have long been considered to be important tools within evidence-based policy and management (Bell et al. 2003; Bell et al. 2008; Hezri et al. 2006). They are a means of capturing complexity into easily digestible 'bits' of information and thus help non-technical minded specialists make use of complex datasets. There is clearly a compromise here between the demands of capturing such complexity in ways that are simple enough to be routinely carried out (Dale et al. 2001). But much depends upon how these datasets are condensed, by whom, and also of course how the indicators are communicated to policy makers and whether or not they are used and for what purpose (Chess et al. 2005). Part of the latter strategy may include the development of indicators that could be picked up by intermediaries such as the press (Morse 2011). Even if the indicators have been well-constructed in a purely technical sense and indeed conveyed to policy makers there is still no guarantee that they will actually be 'used' or indeed have an influence (Bell et al. 2011a; Hezri 2005; Hezri et al. 2006; Hezri et al. 2004; Hopkins 2008;

Turnhout et al. 2007). It is this complex web of connection between creation of indicators at one end and 'usage' at the other which has formed the basis of the EU funded POINT (Policy Influence of Indicators) project. The EU has funded a number of projects focussed on indicators, an example being the project entitled 'Promoting action for sustainability through indicators at the local level in Europe' (PASTILLE), but the POINT project sought to go beyond the development of indicators but instead focus solely upon their use and influence at the policy and managerial levels in the EU and in members states. The PASTILLE project did include a dimension exploring influence of indicators, but this was at local scales (municipalities). The POINT project set out to explore indicator use in a number of sectoral (sustainable development, transport, energy and agriculture) and country (Malta, Slovakia, Finland, Denmark and UK) contexts.

POINT took two different approaches to collating and analysing evidence from key stakeholders and secondary sources. Firstly there were work packages which utilised the standard social science research methods of interviews, surveys and textual analysis of policy documents, reports etc. The results of these work packages are covered within other papers in this Special Edition. Secondly the project included a work package which adopted a more participatory approach to collating insights from stakeholders (Turnhout et al. 2007). A series of workshops were organised within which stakeholders having an interest in indicators were placed into groups of 4 to 5 people and asked to explore what they thought were the key issues in terms of the use of indicators by policy makers. Details as to how this was achieved are set out in Bell and Morse (2011a) and do not need to be repeated here. In part the intention for having two approaches was to provide a different perspective on the question of indicator use given that the dynamics in groups are different from say one-toone interviews and insights often emerge. The workshops also allow for a degree of stakeholder learning and networking.

The aim of this paper is to present findings from the participatory (group work) dimension of the POINT project. The findings are of two inter-related forms. Firstly there are those regarding process - how the participation 'worked' with these groups and what were some of the problems encountered as they delved into their experiences with indicators and tried to share them with others? After all, the analysis arrived at by the groups was an amalgam of their discussions and there are many factors at play here. While there are many insights that emerged from the participatory process, including the importance of group dynamics, the authors have covered these in some depth elsewhere and need not be repeated in this 
paper (Bell and Morse, 2010b). Having said that, the process was important as it influenced the nature of the insights which emerged and hence it is necessary that some of these be covered here. Secondly, and this will form the bulk of the paper, what results regarding indicators and indices emerged from the process? What do the insights from the groups say about those tools and their influence within the EU? Hence the paper is divided into two components. Firstly the authors will flesh out some of the issues that surrounded the group work process but which have not been reported elsewhere. Secondly the paper will explore a number of the insights which emerged from the POINT workshops regarding the use of indicators. But given that the latter is influenced by the former then the two components will inevitably meld into each other and 'results' cannot be separated from 'process'.

\section{Group Work: a conundrum}

Participatory methods have a long antecedence and we are certainly not the first to call for such methods to be adopted to help our understanding of indicators (see Turhnout et al, 2007 , for an example from the pages of this journal). Some say that the first book on participation / participant observation is the Anabasis by Xenophon around 400BC (Professor Simon Goldhill, University of Cambridge, BBC Radio 4, $26^{\text {th }}$ May 2011). Our own work as the basis for the POINT workshops began in a much more contemporary era. The focus for our understanding of participation has been in the area of development and specifically sustainable development. Building off the work of Donald Schon (Schon 1983; Schon 1987), who in turn had been heavily influenced by the action learning thinking of Kolb (Kolb 1984), Robert Chambers of the University of Sussex in the UK provides a massive steer to the participatory literature with the continuum of rapid rural appraisal (RRA), participatory rural appraisal (PRA; later re-coined as participatory rapid appraisal) and participatory learning and action (PLA) - approaches which have been heavily cited and built on in this and other fields (Chambers 1983; Chambers 2002). The participatory literature is extensive, but while participatory approaches, including those that ask participants to engage with each other in small groups, have a high degree of popularity amongst researchers they are certainly not without their challenges and thus do not present a panacea. The RRA-PRA-PLA continuum describe epistemologies rather than specific techniques, and in reality can comprise a range of different tools applied in a variety of ways and time-scales. Key to all of this is 'successful' engagement by participants but there is so much subjectivity here. Indeed the problems of getting groups to engage in productive 'group thinking' are legendary. The following exert from a facilitators diary is instructive of the range of such challenges one often encounters:

"25 minutes into the event and I have three groups working around three tables. One group is relaxed, laughing and sharing conversation in a pleasant and open way. The second group is much more reserved. They look at the first group and then down at the paper on the table before them. They occasionally make eye contact with each other but then shy away. One male is talking but he looks like he is talking to himself. The group looks hugely uncomfortable and lost in the task. I wonder if they will get bored soon? The third group is different again. They are gathered around two senior males and seem happy to be so. I do not talk this language but one male is talking and talking and talking. He seems to be laying down the world and the rights and wrongs of all. His discourse is being attentively listened to by all his group. Some are making notes. Very strange. Ten minutes later and the first group are all standing up and drawing and laughing and chatting. Some go to the toilet and return quickly. Much good humour and fun all round. The second group is now being led by the single male. He is drawing but all the rest seem unfocused and /or bored. The third group is still listening to the lengthy discourse from the dominant male." 
Work Log of one of the authors.

Within this excerpt is the key issue of group dynamics, including dominance by individuals, shyness and reticence. At one end of the continuum groups could end up expressing the views of just one person and those with expertise may have their voices drowned out. This is a well understood problem that many of us encounter in one way or another each day and it will thus be no surprise to the reader that explorations of the downside of group thinking or "Groupthink" have a long history. The term is attributed to William H Whyte who, in 1952 noted:

"We are not talking about mere instinctive conformity - it is, after all, a perennial failing of mankind. What we are talking about is a rationalized conformity - an open, articulate philosophy which holds that group values are not only expedient but right and good as well." (Whyte 1952).

The notion of 'groupthink' as mere 'complacent conformity' in this extract is certainly not flattering. The term 'groupthink' was properly elucidated into theory by Irving Janis (Janis 1972) still largely in negative connotation, for example with reference with the conformity thinking in the CIA which led the US Administration under Kennedy to sanction the disastrous 'Bay of Pigs' invasion. Janis developed a theory for Groupthink based around three key conditions: Group Cohesiveness, Structural Faults (such as insulation of the group and lack of impartial leadership), and Situational Context (for example: stress in external event and failures). In exploring the group Janis thought that combinations of these factors could lead to the negative connotations of group think. Janis went on to develop a model for testing Groupthink based on eight 'symptoms' and his original work has been applied and tested widely in the field. Esser provided a compendium of comparative Groupthink studies (Esser 1998) and largely found that the theory and research around Groupthink had been of great value, if productive of a range of untested further theories. Interestingly, for the POINT workshops, Esser notes:

"Park (1990) pointed out that most of the symptoms of groupthink cannot be assessed easily by an outside observer" (Esser 1998 page 136).

Each of the groups described in this paper were asked to explore indicator use and influence within the EU but their makeup, the mix of individuals within each group in terms of their relative experience with indicators, would be quite different and this may well have influenced the consensus that they arrived at. It will be difficult for outsiders to the group to be able to identify such influences.

More recently others have applied the Groupthink idea as an heuristic to gain insights into group issues and problems, most specifically in decision making (Scharff 2005), and some still question the nature of the dynamics at work in subtle forms of consensus (Packer 2009). In contrast to the 'orthodoxy' of the negative connotation surrounding Groupthink, authors such as Innes and Booher (Innes et al. 2010) and Surowiecki (Surowiecki 2005) suggests that there can be collaborative rationality in the function of groups and 'wisdom of crowds' if the group/ crowd has certain qualities (which contrast interestingly with Janis's three key conditions (the contrast between positive and negative views of the work of the group is commented upon by Berg et al (Berg et al. 2011).

However approached, achieving purposeful group thinking is dogged by weaknesses of various kinds, even when groups are asked to explore a topic as seemingly precise and 
focussed as the use of indicators. Each member will be bringing with them their or experiences of indicators, and perhaps the setting for that experience might be geographically quite local rather than national or even regional and may even be specific to a sector such as transport or energy. Thus even an apparently focussed question can generate many perspectives depending upon context, and some of these can be conflicting. These weaknesses cause all kinds of problems in terms of group efficiency, productivity and resilience. However, good participation (if such a thing can be identified by empirical study) cannot be guaranteed even if it is assumed to be an important requirement of all such processes. The mechanics of group work can be compared to meetings, or writing or even the way we study. It relates to a skill which can be allowed to evolve according to chance but is surely far better learned, applied and considered in a thoughtful and reflective manner. Building on this the authors would suggest that effective participatory group work can be considered from a vast range of standpoints and for a large range of purposes, but in order to understand it and to maximise its potential to strategically advance policy makers effectiveness requires a reflective and thoughtful understanding of the granular/ atomic level of group work.

Indicators are, at least in theory, tools designed to facilitate human discourse and thus have a degree of social construction (Bouleau et al. 2009). As stated at the very onset of the paper, their purpose is to help the flow of information to those who may not necessary have technical expertise related to that information but who are nonetheless expected to make use of it to bring about change. Thus any understanding and interpretation of indicators is meant to be a function of group work, even if the axis is a simple one from indicator generator to indicator consumer. Even in the simplest case where one person both generates and uses the indicator to help guide change there will still be repercussions for others.

Groups have been studied by all kinds of academics in many domains. The studies have a range of names: participant observation, rapid rural appraisal, stakeholder/ community engagement, qualitative research, 'the Fifth Discipline', community based mapping to name just a few. Groups are studied in various contexts: from the group work of psychodynamics (for example see Bion 1961; Bridger 1981), to management texts in the area of group work and learning organisation (Boddy et al. 1992; Lawley et al. 2003; Pedler 1997; Pedler et al. 1991; Pickles 1995). From cognitive diagramming and other varieties of expressive art examples of sound group theory in action (Cybernovation 1990; Marguiles et al. 2002), to information systems (Knight 1989), community development (McIntosh 2008) or operations research (Midgley et al. 2004). We can also include groupwork in the internet and the formation of social groups (networking) in that context (Cordoba-Pachon et al. 2009). The August 2011 riots in some English cities are a particular expression of the power of social networking via Facebook and other media. Without even beginning to explore the meaning and context of texts we have a plethora of possible avenues to examine all of which contain the notion of group thinking and working together in some form of communal action or study. Clearly we cannot claim to have engaged with all of these areas. The work of this paper, and indeed the special edition on the results of the POINT project, is primarily concerned with the ways in which policy making groups form and make effective use of indicators. Our ideas at this stage are exploratory and tentative.

Group work, specifically for the purpose of this paper - group work among mixed professionals, is usually facilitated in some manner or form. Probably emerging from the facilitation process there has been some talk of the importance of 'brokers' to help communicate information between different specialists, for example, technical specialists at 
one end and policy makers at the other (Choi et al. 2009). The 'brokers' may make use of indicators as well as other tools to help achieve this transfer of knowledge. In the domain of Operational Research, Sims, Eden and Jones (Sims et al. 1981) provided some early leads to the problem solving capacities of facilitated groups. The authors clearly defined many issues facing group problem solving and disincentives for facilitators working with such groups. Sims and Eden also saw a key issue for Operational Researchers when it comes to group work, arguing that the researcher could "encompass a facilitator role within their expert problem solving role rather than to become behavioural science consultants" (Sims et al. 1981 page 365). The concern over the role of the facilitator is to some extent picked up by Pidd (Pidd 1988) who, although writing in the domain of problem structuring and implementation, considered that there was a need at the time to "legitimate non-scientific behaviour by practitioners" (Pidd 1988 page 121). Pidd further argued that: "tangible and intangible factors are equally important in achieving successful implementation" (Pidd 1988 page 121 (our emphasis)). Harmon and Rohrbaugh (Harmon et al. 1990) worked with large sample groups and considered the role and function of feedback for groups - most specifically of interest in terms of the current paper, they were concerned with the function of feedback for individual and collective performance. Their reflection, that feedback enhances learning and consensus, is maybe not too surprising. Bostrom et al (Bostrom et al. 1993) evidenced the power and value of good facilitation in problem solving and Phillips and Phillips (Phillips et al. 1993) further emphasised this point, showing the value of the facilitator with the emotional as well as the rational, problem solving aspect of such work. Working from the Operational Research (OR) side of the group working process, the value and purpose of ICT in group work begins to emerge as a strong thread (Beise et al. 1999). However, Phillips and Phillips also note the power of facilitation:

"We believe that through the creative potential of FWGs (Facilitated Work Groups), it is often possible to transform conflict into win-win situations. Without compromise, both organizational and individual objectives can be achieved. But even when this is not possible, effective organizational solutions can often be found in FWGs that are more satisfactory than anything proposed by an individual working alone." (Phillips et al. 1993 page 548).

The value of the facilitation process for individual, group and collective action is now clearly established (Huxham et al. 1994; McFadzean et al. 1998; Morton et al. 2007) and the requisite skills and essential inputs of the facilitator in contexts of systemic interventions has been addressed in detail (Ackermann 1996; Nutt 2002). However, the literature indicates a number of key issues in any group work context. These issues have implications for the group and for the nature of the group thinking which emerges - whether it be the negative observations of 'Groupthink' as noted by Janis or those positive implications of the Wisdom of Crowds noted by Surowiecki.

In order to try to understand what the policy groups studied in the POINT project were achieving and in order to gain some sense of the mechanics at work behind their conceptualisation of their domain of policy use of indicators, we have tried to contain the most vital variables indicated in the literature as being part of a Group Work Algorithm (GWA). We wanted to use this algorithm as a means to assess the groups we worked with in a fairly quick and fairly robust way in order to see if the quality of what the group produced could be simply related to a single variable, or a pattern of interacting variables. 


\section{A suggested Group Work Algorithm}

Without wishing to seek to informalise the objective understanding of group work and output (on the one hand) or to trivialise the complex and systemic nature of the group in all its various aspects (on the other), purely as a sense-making device, we developed the algorithm for considering the basic functionality of the group - along the lines of factors identified in the literature. From what we have seen in the POINT workshops and indeed elsewhere, it could be that a number of factors come together to provide a sense that a group will be able to work in a positive and progressive manner and produce commensurately progressive output. In sequence we might consider these factors as:

- Group Recruitment (GR): how a group is brought together, who is selected and what mix of stakeholders are involved.

- Group Background (GB): the comparative levels of expertise and insight deemed to be present in the group.

- Attendance incentive (Al): the nature of the 'carrot' or 'stick' which is productive in bringing the group together.

- Leadership (L): the degree of control and leadership present in the group.

- Group dynamic tone (GDT): the working tone of the group, an item which can be assessed from the inside out (group self-review) or outside in (external facilitator review). This is an item which we have spent a considerable time discussing in previous papers (Bell et al. 2010a; Bell et al. 2010b; Bell et al. 2011a; Bell et al. 2011b)

- Group output (GO): the qualities attributable to the group's output - this is an issue which we will spend some time considering in the remained of this paper.

If each of these factors were to be considered in terms of a sliding scale it might appear as shown in Figure 1.

$<$ Insert Figure 1 about here>

The Group Work Algorithm or GWA suggested by this paper is as follows:

$$
G \mathcal{R}+\mathcal{G} \mathcal{B}+\mathcal{A} \mathcal{I}+\mathcal{L}+G \mathcal{D} \mathcal{T}+G O=G \mathcal{G} \mathcal{A}
$$

Note how GWA has been set out in terms of the addition of its components. We acknowledge that this is arguably simplistic as some of the components, if not all of them, may interact. It must also be noted that we have selected and tested this algorithm purely as an experimental attempt to make some sense of the group work we experienced, and as a means to cross check this against other criteria we were applying. What we set out below is a retrospective test of the groups and to assess this against the 'windows on the mind' provided by Rich Pictures described in the following section.

\section{POINT and the Algorithm}

How did the Group Work Algorithm apply within the POINT project? In terms of group recruitment the POINT project took a compartmentalised approach whereby team members within each participating country organised their workshop, including the logistics of location, timing and choices over who to recruit. The authors were then invited to travel to the country and run the workshop, usually over a total of 3 days ( 1 day for planning and 2 days for the workshop). The logic behind this division of labour was clear. Members of the POINT team in each country had the best local knowledge as to who should be involved (and 
why) and where best to hold the workshop so as to help encourage these people to attend. The 'indicator' community in each country was inevitably a large one, spanning all tiers of government, NGOs, academia, industry and so on, and hence it would simply not be possible for someone outside that environment to have anything like the local knowledge of those working on a day-by-day basis within that context. This devolution of participant selection also had a bearing on the background of those attending the workshops, but this was also driven to a large degree by the decisions of those invited. Many invitations were sent out to possible participants, in one case this was literally in the hundreds, but not all those invited attended. Those who did attend often gave reasons such as 'interest' in indicators, of course, but also an interest in the participatory process and a desire to meet others in the indicator community. Indeed some said that they attended primarily to learn about the process and didn't expect to learn all that much that was 'new' about indicators! Admittedly the latter view often changed and participants who thought that they knew all there was to know about indicators often expressed astonishment at the end of the workshop about some of the views and opinions held by others and felt that they had learnt much - the learning often being of both a technical but, more importantly, of a personal level (comments such as: "I have never spoken to these people before", were common). The indicator world is a large one and even people working with the same sets of indicators (e.g. environmental quality or economic growth) can have quite different perspectives on their usefulness. Despite these issues, the authors provided local project staff with a stakeholder selection criteria which was designed in order to achieve a balanced selections of stakeholders for each group (in terms of a mix of professions, a balance of different concerns (e.g. lay persons, representatives of NGOs, public, private agencies, etc.) and a range of expertise. All groups have an interest in policy and represent a number of different countries in the European Union. We aimed for groups to be between 5 and 8 people.

Some of the workshops that were held in the POINT project are set out as Table 1. For convenience the groups have been given codes (A, B, C etc.). For the sake of brevity and illustration we have focussed on seven out of the POINT groups rather than present all of them. While the theme of each workshop was the same - the use of indicators - it can be seen from Table 1 that workshops differed in terms of the sectors within which indicator use was being explored. Some focussed on indicator use in sustainable development, while others explored sectors. Table 1 also shows the number and type (in terms of occupation) of participants in the groups. The workshops largely comprised participants from the public sector, including researchers, academics and students, and the private sector is perhaps under-represented. The authors did not organise the group membership; this was achieved by the participants. Neither did the authors suggest how each group should function, other than to guide them through the steps of the workshop process. Group dynamics was an important aspect of the POINT workshops and as mentioned earlier the authors have already written extensively about this (Bell et al. 2010a; Bell et al. 2010b; Bell et al. 2011a; Bell et al. 2011b). Needless to say there were both good and bad group dynamics at play within each workshop. This is a useful point at which to briefly note our approach to 'good' and 'bad' in terms of dynamic. Without going into a lengthy debate on the nature of what it is to be good as opposed to bad, our understanding in this paper is to note 'good' as referring to qualities such as functional, productive, insightful, critical, tolerant (for example as exemplified in Wenger 1999; Wenger et al. 2002), whereas we would note 'bad' dynamics as evidenced by intolerance, bullying, lack of output, hyper-critical, lack of insight, narrow and/ or predetermined thinking, false consensus (as evidenced in much of the groupthink literature. Clearly few groups will be entirely good or bad but a mix of both qualities. Part of the mix in this case is the presence of leaders within groups. In some cases a leader emerged within a group for a variety of reasons. Maybe because the group members were happy for 
one of their number to take charge and effectively impose their views on the others, albeit with their acceptance. In some cases this was because that person was thought to have a higher degree of knowledge about indicators, perhaps because of their standing (leading academic for example) or because of their day-to-day work. Thus it was certainly the case that the groups were different in terms of the components of the GWA. Figure 2 provides an overview of the use of the GWA in the case of the seven groups listed in Table 1. The group codes ( A, B, C etc.) have been kept consistent across Table 1 and the various figures. Our intention is to provide a reader with an example of how the GWA could be populated and what insights it could provide.

$<$ Insert Table 1 and Figure 2 about here $>$

Based upon this admittedly subjective and partial analysis, the groups are fairly well clustered with Group E best performing across the criteria and Group $\mathrm{C}$ appearing to be lowest scoring. Our questions follow on:

- How do these observed factors relate to our interpretation of the groups analysis?

- Is there a 'killer factor' which helps us to understand the key dynamic which provides insights into the work of the group?

- Can a groups' likely output be guessed by observing the work of the group and so;

- Does our algorithm provide a set of factors which explains the tendency of the group to the negative connotation of groupthink or the positive vision of the wisdom of crowds?

However, this review of process can also be compared to a more qualitative assessment of the output as revealed by the rich pictures.

\section{Picture as window of the Groupmind: exploring indicator use}

It is not possible in this brief article to present all the outputs of the group process as implemented within POINT. The data collected within each of the workshops in Table 1 was substantial, including audio-visual material (pictures, recordings), notes and assessment of the group dynamics and interviews held at the end of each workshop. Rather than attempt to present all of this the emphasis here will be upon one phase of the workshop; that held at the very start of the process where participants are asked to 'scope' out the combined breadth of knowledge and insights they have regarding what they think are the key aspects of indicator use in policy. At the very start of the workshop each group was presented with a large sheet of paper and set of coloured pens and asked to capture this shared insight into a 'rich' picture. The idea is to capture the breadth of issues, in a 'no holds barred' sense, that may be considered important by the group. The groups are encouraged to use as little text as possible and thus to use symbols and pictures to express the points they wish to make, with lines to connect any which they feel are especially related. Some pictures were undoubtedly richer than others, both in aesthetic terms (e.g. in terms of use line, colour, icons and icon combination) as well as the narrative of the story being told and of emergent insights (see for example the various discussions in: Avison et al. 1992; Campbell Williams 1999; Fougner et al. 2008; Lewis 1992), but what emerged in each case provided much food for thought. It should be remembered that the rich pictures are negotiated and hence agreed positions; they are the outcomes of participation. Not all within a group may 
necessarily agree with what is in the picture or indeed what is missing, and indeed in many cases the content of the picture will emerge out of a long discussion. Thus the process of creating a rich picture, even those that might seem quite basic, may take hours rather than minutes and not necessarily be emblematic of consensus. Indeed, the rich picture may itself tell a story of divergence of view and disagreement over key themes.

The authors have selected a few rich pictures which provide some interesting insights regarding the use of indicators. The rich pictures that have been selected are presented as Figure 3 and each has been given a subscript (A, B, C etc.) which matches the codes in Table 1 and Figure 2 . Below we set out a narrative description of each picture and its various qualities.

$<$ Figure 3 near here>

The rich picture for Group A makes a distinction between indicators that 'people with power care about', such as Gross Domestic Product (GDP) and those which the group thought were commendable but 'hidden', such as the Genuine Progress Indicator (GPI) and Index of Sustainable Economic Welfare (ISEW) and their link to some notion of social justice (GPI and ISEW were initially derived as fairer alternatives to the GDP). Note how the latter are shown at the bottom right of the rich picture and are purposely hidden under a dark line. But why are some indicators hidden like this? The group had a number of angles on this question. Firstly note the pictures on the left - see no evil, hear no evil and speak no evil. This represents almost a hidden consensus for policy makers to only look at the indicators (and indeed issues) that matter to those with power (represented by the stringed puppet on the right). Economic wealth 'matters' to these powerful groups and hence GDP becomes the key indicator adopted by policy makers to measure that property. The things which are measured by GPI and ISEW simply don't matter to those with power and thus while all know that they are there they are not seen, heard or spoken of. Thus the picture has a deep sense of power relationships embedded within it and the outcome is something that does matter for ordinary people (note the family at the bottom right) as well as the environment (bottom left). Issues of dominance of a particular vision and the rules of indicator usage surrounding that vision emerge from the rich picture. The group was mid-scoring in the GWA with strengths in wide team background, group leadership, dynamics of the group and rich picture. The group comprised a mix of government, NGO and researcher, but seemed to be led by the student member. This was seen in a number of the POINT groups; a leader would emerge who may not necessarily be the most senior of the members.

The picture for Group B is another strong story about the use of indicators for decision making and provides an active description of how politicians (this time in the centre of the picture) seek to use indicators. Note the many influences at play here, from the EU (top left), money (centre left), business (top centre), science and academics (right) and indeed the public (bottom right). The key point for this group is that all of these influences are themselves intertwined with lots of lateral influence. These influences act as pressures that 'select' indicators and the group arrived at what it called the "indicator life cycle" whereby indicators might have a limited period of use followed by decline and eventual death. Thus in the opinion of the group it is a mistake to think of all indicators as long lasting. Indeed they took this idea further and raised the notion of an 'ecology of indicators' whereby some related indicators may reinforce each other in terms of use and the pressures can provide a selection process; a notion of 'survival of the fittest' for indicators, and again this resonates to notions of dominance and the way in which different indicators 'rise' to prominence. Scoring the same as Group A in the algorithm the group again had a rich set of stakeholders 
present, although having a stronger 'academic' representation than did the others groups, and exhibited good leadership and outputs in terms of the qualities in the rich picture.

Group $C$ has indicators rather than people at the centre. It is a series of vignettes with poor connection between them. Just to the right of the centre is a representation of the need to define sustainable development before one can create and use indicators to help achieve that objective. This particular group were charged with looking at indicators within the context of sustainable development so that emphasis is perhaps unsurprising. Indeed the group saw the issue of definition as a major problem with the use of indicators to help achieve sustainability; an imprecise and movable definition can lead to a multitude of sometimes competing indicators. Communication of indicators is covered by the vignettes at the bottom right and bottom centre. The group saw an important interface between government and research, and information users and producers need to understand each other although in the eyes of the group this has not yet happened. Indeed the picture at bottom centre (person with a light bulb) implies that indicators should be part of a learning process for both government and research. The chimney pipe and $\mathrm{CO} 2$ just to the right of that person implies that some indicators are easy to see and thus have a more natural appeal for both government and researchers, but some are not so easy to appreciate. Hence the graph at the bottom right with its complex peaks and troughs implies that some phenomena are hard to understand given our current state of knowledge. These complex patterns are important but the group questioned the point of an indicator that tries to capture this complexity if no one really understands the causes. Indicators can have positive and negative trends over time as shown by the two graphs to the right of the centre but the interpretation of such patterns can be biased and this raises questions as to the potential for indicators to be a part of a manipulation process. Towards the top right of the picture are a series of maps that stress the need for different indicators at different scales (local, national and international) and to avoid a 'one indicator fits all' approach just for the sake of simplicity. We define this group having issues over the rules of indicator use and a certain disconnection between users and producers. Group $\mathrm{C}$ were the weakest of the groups in the algorithm analysis with a particularly low score for the quality of the rich picture. Ironically the group was dominated by national and local government staff, all of whom had lots of practical experience with indicators albeit at different scales. Indeed the discussions within the often became quite heated as a result of this 'conflict' between indicator sets and methods at local and national scales.

The Group D rich picture is very diverse. Eurostat is featured in the picture towards the bottom and is portrayed as a good and reliable source of information, but many people do not understand what indicators mean (vignette towards the bottom/centre right). They can be used as a help to change behaviour but at present the group feels that this connection does not really work. They suggest the use of the media (top centre) such as television to help spread get information out but there is also an acknowledgement in the picture that citizens are a varied group, spanning those that are active and passive, and there is a danger of confusion with multiple (and sometimes competing) messages being purveyed via indicators. Towards the bottom centre there is a representation of the ecological footprint which the group thought was an especially good way of conveying information, although surrounding it are questions about how it can be best used to encourage consumers to change their way of living. The issue of dominance emerges yet again but this time it was linked to the need for rules to prevent conflicting messages being promoted. This group had a high scoring group on the algorithm analysis, with good scores in all areas. Group D took part in the Finland workshop, the same one that included Group C, but comprised a more 
diverse mix of participant, including NGO staff as well as an academic. The NGO members in particular brought in some interesting insights and ideas.

Group E's picture has some resonance with that of Group A but here there is a very strong sense of indicators being linked to truth and indeed justice. The scales of justice dominate the bottom part of the picture, and at either side there are the various entities assessed by indicators with the people pictured hanging on the scale being those that do the measuring and thus having some influence over the relative weighting in the balance. The group argued that while in their view people are very good at making and measuring indicators they do not necessarily result in justice and an adequate balance between aspects of life. For example, while they may be a perceived need for a green agenda with associated indicators will others, including politicians (centre right in the picture), really want to hear what the indicators say and adjust the balance to suit? Hence there is an implied sense of the balance being controlled by people making selective use of indicators. Note the two-way arrow between the politicians and the researchers (those creating the indicators) in the top left of the picture. This suggests that researchers are themselves intertwined with politicians in the sense that the latter has control over funding and hence agendas; it is not a one-way process of influence. We can to some extent reduce this complexity to issues of dominance, rules and a disconnect between the various pressures within the 'indicator eco-system'. This informative work contributed to the group being the highest scoring in terms of the algorithm. The group had a diverse membership which included someone from the private sector.

The picture for Group $\mathrm{F}$ is one of the more complex of those presented here. The underlying theme of the picture is one of problems with responsiveness to change. Entire processes have been developed to collect and provide information to decision makers and indeed the public but given the size and diversity of the EU can change really be made to the suit of indicators and data they require to match any change in thinking? Thus while the picture has a number of sectors (transport, energy, education) and required behaviours the centre piece of the picture is the flow of information. Hence some indicators do 'well' in this complex set of interactions and have a degree of longevity (partly through inertia) while others do not. There is some resonance to the 'ecology of indicators' idea mentioned earlier but with one of the factors that govern survival simply being the difficulty of bringing about change leading in inertia. Issues of disconnection and problems with dissemination emerge. This is a mid-scoring group in terms of the algorithm.

The final picture, that of Group G, also has a strong emphasis on indicators but this time provides one of the more sceptical views as to the potential for such simple (by definition) tools to capture real world complexity. There are many indicators already in existence and there is a pyramid of people both using and providing indicators with many feedback loops operating between them. The result is a cacophony of 'signals' having to be digested by indicator users. This picture presents a message of chaos; lack of rule, disconnection between elements of the indicator eco-system, ambiguity (another background theme in the pictures above) all conspire to generate the cacophony. As with group $F$, this group was mid scoring in terms of the algorithm. It was the only one to have representatives of the European Commission; the body that had commissioned the research.

\section{Discussion}

The use of the participatory workshops in the POINT project certainly raised lots of interesting ideas about indicators and their use. Admittedly these are of a very general 
nature and to some extent there is overlap between the stories told in the rich pictures. Thus there are recurring themes of power which emerge, albeit in slightly different forms, and the dominance of indicators such as GDP is well known. Politicians obviously have much power as they can influence decisions over what indicators are needed as well as how the information is used to bring about change. Politicians are also subject to many influences and not just from indicators. These are far from being new insights, and indeed have often emerged from other work packages in POINT. But the notion that indicators are part of a 'ecology' whereby related indicators 'groups' can exist together and provide mutual support and each indicator is subject to a selection pressure which means that they can live or die does provide an interesting and novel conceptualisation. Indicator 'success' in this struggle for survival was very much seen in terms of whether it is quoted, mentioned and reported on an ongoing basis. The selection pressures are varied and the implication is that even poorly developed indicators (in a technical sense) can survive and prosper if the demand for them is there. One group also raised the importance of inertia as part of this; indicators can survive simply because it is difficult to change them. Indeed this conceptualisation of indicators 'red in tooth and claw' does help with an appreciation as to why some are readily adopted and become successful in bringing about change while others do not. Even a technically 'bad' indicator can do well in this struggle for attention and hence survival. If a purely technical perspective is taken over whether an indicator should survive or not then this may seem bewildering but a broader notion of an 'indicator ecology' provides a ready explanation which would seem worthy of further exploration in subsequent research.

Also of interest was the overt linking of indicators to highly subjective values of truth and justice, especially by one of the groups. Thus indicators as a tool to help with both communication of evidence to policy makers and managers as well as a means for them to chart the consequences of their actions are also deeply imbued with the need to make sure that those actions help ensure justice so that one group in society is not disadvantaged to the benefit of others. Sustainable development has that sense of justice as a central concern, development that takes place in the current generation should not disadvantage future generations, but the need to ensure that indicators are part of that also takes them away from being purely technical and objective 'objects' to being intertwined with human value. In many ways these comments about the social construction ('messiness') of indicators reinforce and indeed extend points already made by authors such as those of Turnhout et al. (2007) and Bouleau et al. (2009) in earlier volumes of this journal.

In another paper (Bell and Morse, 2011a) we have summarised the totality of outputs from all the POINT workshops by employing what we have called the ' $5 \mathrm{Ds}$ '.

- Disconnect between indicators and their influence in policy.

- Dominance of more narrow worldviews such as the GDP example given above.

- Dissemination which includes the need for appropriate presentation of indicators given the target groups trying to be reached

- Disambiguation which covers issues such as data availability issues and opaqueness of existing indicators which makes them difficult to appreciate.

- Dictum which includes the need for clarity (rather than ambiguity) as to what it is we are trying to measure with indicators.

These points are consistently raised in the rich pictures set out here and constitute a high level overview of the learning from the workshops. 
Regarding process, an interesting insight is the lack of a strong link between the factors which we noted for the algorithm and the value of the rich picture output. A good rich picture and a low algorithm score can go hand in hand (e.g. Group G). What we have is something much more interesting going on that a crude linkage between 'functional group and good output'. Clearly more thought and analysis is needed but the group's conditionality in terms of its membership, reasons for participating, leadership and recruitment do not appear to be the key criteria for the performance of the group. It may be that they help to contribute but it would appear from this analysis that these are not the determinants for understanding why a group will or will not produce a viable and /or dysfunctional outcome. With this in mind and returning to our original questions, we can provide these observations:

- How do these observed factors relate to our interpretation of the groups?

- The factors do not have a linear relationship to the group dynamic

- Is there a 'killer factor' which helps us to understand the key dynamic which provides insights into the work of the group?

- Definitely not.

- Can a groups likely output be guessed by observing the work of the group and so;

- It would seem not.

- Does our algorithm provide a set of factors which explains the tendency of the group to the negative connotation of groupthink or the positive vision of the wisdom of crowds?

- Again, this would seem to not be the case.

So, given our null response, how is such information useful? The algorithm was applied after each workshop and thus could not be used to help intervene during the workshop. Certainly the lessons learned from one workshop could be applied to help improve following ones, and indeed that did happen in the POINT project which involved a series of related participatory workshops. There are tensions here of course as on the one hand it can be useful to compare and contrast results between workshops, but on the other hand what really matters are the insights the groups arrived at in terms of indicator usage. Thus it was not necessary to have an immutable process which stayed constant in the face of lessons learnt. The groups were variable in terms of age, profession and expertise but, no single factor seems to have been obviously central to the productivity of a group. This implies to us that if we are to try to gain a deeper understanding of not just 'what' a group produces but also 'how' and 'why' it does what it does, we need to look below the surface for the kinds of factors which we could place into an heuristic device such as the GWA.

In the approach which we adopted in our workshops, participatory methods generate many novel insights precisely because each group is quite literally presented with a blank sheet. Thus they are not constrained by having to provide answers to discrete questions set by the researcher. The insights they arrived at are intertwined with the process of getting to those insights. Given the 'messy' nature of indicators mentioned earlier this provides an important advantage. Indeed as Turnhout et al (2007; page 228) have stressed:

"For an effective development and use of ecological indicators, quality as well as acceptance is very important and the inclusion of stakeholder perspectives can be an important contribution to both........ Stakeholder involvement should start in the early phases of the process at the level of problem formulation." 
Even with semi-structured interviews where questions act as a sort of checklist the conversation is still governed by the researcher and they can take it in any direction they wish. Pilot studies can help with re-direction of course, but it is still a researcher-driven exercise in terms of what is asked and what is listened to. Similarly with textual analysis it is the researcher who decides what to look for (i.e. what to code). The process may be a deductive one whereby the questions are governed by a series of hypotheses (or expectations) or inductive where the research may have no prior expectation but simply sees what emerged, or a combination of both. With indicators there are dangers with assuming that we know what the issues constraining or helping usage will be and creating approaches designed to test them. Given the social construction of these tools this can miss many broad insights such as those provided by the rich pictures. Indeed the approach taken in the workshops was more 'eductive' in that the ideas and thoughts of the participants were 'drawn out' rather than being suggested or implied by the research question.

There remains the problem of understanding why a group does what it does. For this a more subtle approach may be useful than that which is provided by the strictures of the GWA. Surowiecki suggests that the 'wisdom of crowds' is to some extent explainable by four interrelated factors:

"diversity of opinion (each person should have some private information, even it its just an eccentric interpretation of the known facts), independence (people's opinions are not determined by the opinions of those around them), decentralization (people are able to specialize and draw on local knowledge), and aggregation (some mechanism exist for turning private judgements into collective decision)." (Surowiecki 2005 page 10)

The GWA was built on commonly applied measures of group dynamic (leadership, group background, attendance incentive, etc.). The inability of the GWA to account for variation in group output indicates that many objective measures for assessing groups are possibly less useful than they might appear at first sight. Maybe, it is in finding evidence for the range of 'soft' factors described by Surowiecki, which can be as evident in a homogeneous as it is in a heterogeneous group, which will provide us with a key to understanding how and why a group moves from groupthink to wisdom?

\section{Conclusions}

In this paper we have been concerned with what groups of policy makers think in relation to their use of indicators. As part of this research we were interested to explore not only what the groups delivered in terms of analysis but factors around group function such as:

- how to get people to assemble?

- How is the group motivated?

- What is the inducement?

- How do groups work?

- How can group work be assesses and, finally,

- how is a 'good' group identified?

In short, we were interested to see if these factors emerged as being important in defining how positive crowd 'wisdom' and not negative groupthink could be achieved. We have argued that this is an area requiring particular scrutiny because the policy use of indicators the function of the group becomes more critical in an age of transparency in decision 
making. This 'age' it seems to us calls for more evidence-based policy and so the importance of good group work to make use of and develop evidence-based policy is consistent and even vital.

The groups with which we worked provided some interesting insights into their experience of the use of indicators in policy situations. The notion of power, in a variety of guises was a key theme, and was centrally linked and most visible with the dominance of GDP. Various groups showed a fixation on the dominance of conventional indicators and this in turn could be argued to imply that a prevailing mindset may be at work. In group situation this could in turn lead to the kind of negative aspects which tend to be linked to notions of groupthink (and evident in examples of poor thinking such as the 'Bay of Pigs' and WorldCom's accounting fraud). After all, indicators which are already in place and which are seen as trusted or absolute can only provide an indication of that which they are intended to measure. They cannot provide guidance on issues outside their role. Blinkered adherence or prejudiced advocacy of a conventional indicator mantra may lead good groups to come to bad decisions.

The groups did also note some interestingly positive tones. Notions of an ecology of indicators as a conceptualisation helps point to the kind of diversity which Surowiecki advocates. Other themes of a lack of clarity around definitions, rules and a lack of opportunity to discourse around issues also point to some positive learning.

In terms of how the groups did what they did, we come to no firm conclusions. The Group Work Algorithm was deliberately designed to pick up on issues which emerged in the literature (e.g. leadership, homogeneity, incentive, etc.) but, these relatively straightforward items did not seem to form any strong patterns in terms of what the groups achieved. The qualities of the Rich Pictures did not consistently relate to our assessment criteria of the dynamic which the group expressed. We think that this is an important observation. The null relation would indicate that much of the evidence relating to group behaviour expressed in the literature is less than adequately explained by these conventional criteria. Whether this is a case of the forces at work behind the groups activity not being relevant to the work of the group or, and we favour this argument, that devices like the algorithm are not sensitive enough to pick out these forces remains a matter for further research. We are seeking to further explore the subtle relationship between group dynamic and group output by means of a methodology called 'Triple Task' (Bell and Morse, 2010b). 


\section{References}

Ackermann, F. "Participant's Perceptions on the Role of Facilitators Using Group Decision Support Systems," Group Decision and Negotiation (5:1) 1996, pp 93 - 112.

Avison, D. E., Golder, P., and Shah, H. "Towards an SSM Toolkit: rich picture diagramming," European Journal of Information Systems (1:6) 1992, pp 397 - 408.

Beise, C., Neiderman, F., and Beranek, P. "Group Facilitation in a Networked World," Group Facilitation (1:1) 1999, pp 33 - 44.

Bell, S., and Morse, S. Measuring Sustainability: Learning from Doing Earthscan, London, 2003.

Bell, S., and Morse, S. Sustainability Indicators: Measuring the immeasurable Earthscan, London, 2008.

Bell, S., and Morse, S. "Rich Pictures: A means to explore the 'Sustainable Mind'?," Sustainable Development (Wiley Online) 2010a.

Bell, S., and Morse, S. "Triple Task Method: Systemic, reflective action research," Systemic Practice and Action Research (23:6) 2010b, pp 443 - 452.

Bell, S., and Morse, S. "An Analysis of the Factors Influencing the Use of Indicators in the European Union," Local Environment) 2011a.

Bell, S., and Morse, S. "Being, Engaging, Contextualising and Managing: BECM Matrix - a means to assess group dynamics?," Systems Research and Behavioural Science (28:4) 2011b, pp 319 - 339.

Bell, S., and Morse, S. Resilient Participation: Saving the Human Project? Earthscan, London 2012.

Berg, T., Pooley, R., and Queenan, J. "Achieving Consensus within SSM," International Journal Humanities and Social Science (1:4) 2011, pp 231- 239.

Bion, W. R. Experiences in Groups and Other Papers Basic Books, New York 1961.

Boddy, D., and Buchanan, D. Take the Lead: Interpersonal skills for project managers Prentice Hall, London, 1992.

Bostrom, R., Anson, R., and Clawson, V. "Group Facilitation and Group Support Systems," in: Group Support Systems: New perspectives, L. Jessup and J. Valacich (eds.), Macmillan, New York 1993.

Bouleau, G., Argillier, C., Souchon, Y., Barthelemy, C., and Babut, M. "How ecological indicators construction reveals social changes-The case of lakes and rivers in France.," Ecological Indicators (9:6) 2009, pp 1198 - 1205.

Bridger, H. Consultative Work with Communities and Organizations: Towards a Psychodynamic Image of Man Aberdeen University, Aberdeen 1981.

Campbell Williams, M. "Rich pictures on the path towards systemic being," Systems Research and Behavioural Science (16:4) 1999, p 369.

Chambers, R. Rural Development: Putting the Last First Harlow, London 1983.

Chambers, R. Participatory Workshops: A sourcebook of 21 sets of ideas and activities Earthscan, London, 2002.

Chess, C., Johnson, B., and Gibson, G. "Communicating About Environmental Indicators," JOurnal of Risk Research (8:1) 2005, pp 63 - 75.

Choi, S. H., and Bae, S. M. "Strategic Information Systems Selection with Incomplete Preferences: A Case of a Korean Electronics Company," The Journal of the Operational Research Society (60:2) 2009, pp 180-190.

Cordoba-Pachon, J., and Ochoa-Arias, A. (eds.) Systems Thinking and E-Participation: ICT in the governance of society. Information Science Reference London, 2009.

Cybernovation Thinking with Hexagons: users manual Cybernovation Technologies and Industries Publication, London., 1990. 
Dale, V., and Beyeler, S. "Challenges in the Development and Use of Ecological Indicators," Ecological Indicators (1) 2001, pp 3 - 10.

Esser, J. K. "Alive and Well after 25 Years: A Review of Groupthink Research," Organizational Behavior and Human Decision Processes (73:2-3) 1998, pp 116-141.

Fougner, M., and Habib, L. "If I had a rich picture: Insights into the use of "soft" methodological tools to support the development of interprofessional education," Journal of Interprofessional Care (22:5) 2008, p 488.

Harmon, J., and Rohrbaugh, J. "Social judgment analysis and small group decision making: Cognitive feedback effects on individual and collective performance," Organizational Behavior and Human Decision Processes (46:1) 1990, pp 34-54.

Hezri, A. "Utilisation of sustainability indicators and impact through policy learning in the Malaysian policy processes," Journal of Environmental Assessment Policy and Management (7:4) 2005, pp 575 - 595.

Hezri, A., and Dovers, S. "Sustainability indicators, policy and governance: Issues for ecological economics," Ecological Economics (60) 2006, pp 86 - 99

Hezri, A., and Hasan, M. "Management framework for sustainable development indicators in the state of Selangor, Malaysia," Ecological Indicators (4:287 - 304) 2004.

Hopkins, R. The Transition Handbook: From oil dependency to local resilience Green Books, Totnes, 2008.

Huxham, C., and Cropper, S. "From many to one--and back. An exploration of some components of facilitation," Omega (22:1) 1994, pp 1-11.

Innes, J., and Booher, D. Planning with Complexity: An introduction to collaborative rationality for public policy Taylor and Francis, London, 2010.

Janis, I., L. Victims of Groupthink: A psychological study of foreign-policy decisions and fiascoes Houghton Mifflin, Oxford 1972.

Knight, K. Participation in Systems Development Kogan Page, London, 1989.

Kolb, D. Experiential Learning: experience as the source of learning and development Prentice-Hall, London, 1984.

Lawley, J., and Tompkins, P. Metaphors in Mind: Transformation through symbolic modelling The Developing Company, London, 2003.

Lewis, P. J. "Rich picture building in the soft systems methodology," European Journal of Information Systems (1:5) 1992, pp 351 - 360.

Marguiles, N., and Maal, N. Mapping Inner Space Corwin Press, Thousand Oaks, CA, 2002.

McFadzean, E., and Nelson, T. "Facilitating Problem-solving groups: a conceptual model," Leadership and Organization Development Journal (19:1) 1998, pp 6 - 13.

McIntosh, A. Rekindling Community: Connecting People, environment and spirituality Green Books, Totnes, Devon, 2008.

Midgley, G., and Ochoa-Arias, A. Community Operational Research: OR and Systems Thinking for Community Development Kluwer Academic, London, 2004.

Morse, S. "Harnessing the Power of the Press with Indices," Ecological Indicators (11:6) 2011, pp $1681-1688$.

Morton, A. F., Ackermann, F., and Belton, V. "Problem structuring without workshops? Experiences with distributed interaction within a PSM process," Journal of the Operational Research Society (58) 2007, pp 547 - 556.

Nutt, P. C. Why Decisions Fail: Avoiding the Blunders and Traps that lead to debacles BerrettKoehler, San Franscisco, 2002.

Packer, D. "Avoiding Groupthink: Whereas weakly identified members remain silent, strongly identififed members dissent about collective problems," Psychological Science (20) 2009, pp 546 - 548. 
Pedler, M. "Interpreting Action Learning," in: Management Learning: Integrating perspectives in theory and practice, J. Burgoyne and M. Reynolds (eds.), Sage, London, 1997.

Pedler, M., Burgoyne, J., and Boydell, T. The Learning Company: a strategy for sustainable development. McGraw-Hill, Wokingham, 1991.

Phillips, L. D., and Phillips, M. C. "Faciliated Work Groups: Theory and Practice," The Journal of the Operational Research Society (44:6) 1993, pp 533-549.

Pickles, T. Tool Kit for Trainers Gower, London, 1995.

Pidd, M. "From Problem-Structuring to Implementation," The Journal of the Operational Research Society (39:2) 1988, pp 115-121.

Scharff, M. "Understanding Worldcom's Accounting Fraud: Did Groupthink play a role? ," Journal of Leadership and Organizational Studies (11:3) 2005, pp 109 - 118.

Schon, D. The Reflective Practitioner: How professionals think in action. Jossey-Bass, San Francisco, 1983.

Schon, D. Educating the Reflective Practitioner Jossey-Bass, San Francisco, 1987.

Sims, D., Eden, C., and Jones, S. "Facilitating problem definition in teams," European Journal of Operational Research (6:4) 1981, pp 360-366.

Surowiecki, J. The Wisdom of Crowds: Why the many are smarter than the few Abacus: New Edition, London, 2005.

Turnhout, E., Hisschemoller, M., and Eijsackers, H. "Ecological Indicators: Between the two fires of science and policy," Ecological Indicators (7:2) 2007, pp 215 - 228.

Wenger, E. Communities of Practice: Learning, meaning and identity Cambridge University Press, Cambridge, 1999.

Wenger, E., McDermott, R., and Snyder, W. Cultivating Communities of Practice: A guide to managing knowledge Harvard Business School Press, New York, 2002.

Whyte, W. "Groupthink," Fortune Magazine (March) 1952. 
Table 1. Composition of some of the workshop groups in the POINT project

\begin{tabular}{|c|c|c|c|c|}
\hline $\begin{array}{l}\text { Workshop topic (use of } \\
\text { indicators in......) }\end{array}$ & Location & Dates & $\begin{array}{l}\text { Group } \\
\text { code }\end{array}$ & Type of participant \\
\hline Agriculture & Slovakia & $15^{\text {th }}$ and $16^{\text {th }}$ April 2009 & $\mathrm{~B}$ & Res, NGO, Ac, Ac, Ac, Gov, NGO \\
\hline Sustainable Development & & & $\mathrm{D}$ & LGov, LGov, NGO, Ac, NGO \\
\hline \multirow[t]{2}{*}{ Transport } & Denmark & $26^{\text {th }}$ and $27^{\text {th }}$ November 2009 & $\mathrm{E}$ & PvS, Res, LGov, Gov, NGO \\
\hline & & & $\mathrm{F}$ & PvS, PCon, Gov, Res, Res, Gov \\
\hline
\end{tabular}

Participant codes

\begin{tabular}{ll} 
Code & \\
\hline PvS & Private sector \\
PCon & Private consultant \\
Gov & Government employee (public sector) at the national level \\
Res & Researcher \\
Ac & Academic \\
LGov & Local Government \\
EC & European Commission \\
NGO & Non Governmental Organisation \\
Stu & Student \\
\hline
\end{tabular}


2

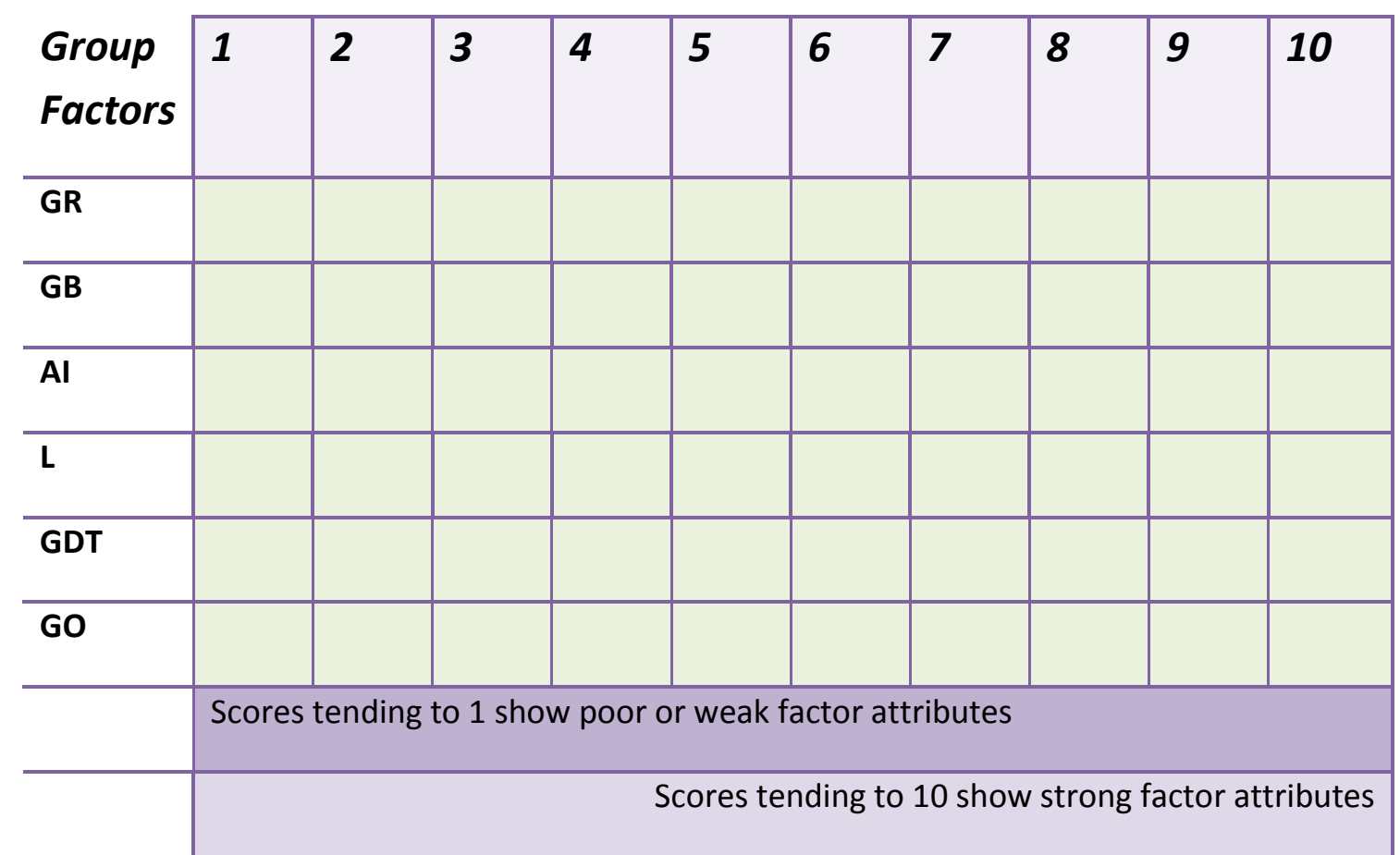

3

4

5

6

7

Where:

Poor Group Recruitment = lack of advertising and/or lack of strong organisation to get group to form

Good Group Recruitment = Highly organised recruiting process

Poor Group Background = highly homogeneous group. Very little variation in the group in terms of work experience

Good Group Background = highly heterogeneous group.

Poor Attendance Incentive = lack of formal (e.g. time, money) or informal (networking, meeting important people, etc) reasons to attend.

Good Attendance Incentive = clear personal value in attending and contributing to the group work.

Poor Leadership = Tyranny, ambivalence or lethargy as the main features of the group leadership

Good Leadership = Informative, empathetic and engaged group leadership Poor Group Dynamic Tone = silent and moody, absenteeism and constant 'churn' Good Group Dynamic Tone $=$ Friendly and inclusive Poor Group Output = outputs are extensions of the terms of reference and do not develop the main themes.

Good Group Output = outputs are step changes from the Terms of Reference for the group. 
Figure 2. Applied Algorithm for six groups

\begin{tabular}{l|l|l|l|l|l|l|l|}
\begin{tabular}{l} 
Group \\
\cline { 2 - 4 }
\end{tabular} & $\begin{array}{l}\text { Group } \\
\text { F }\end{array}$ & $\begin{array}{l}\text { Group } \\
\text { B }\end{array}$ & $\begin{array}{l}\text { Group } \\
\text { C }\end{array}$ & $\begin{array}{l}\text { Group } \\
\text { D }\end{array}$ & $\begin{array}{l}\text { Group } \\
\text { E }\end{array}$ & $\begin{array}{l}\text { Group } \\
\text { F }\end{array}$ & $\begin{array}{l}\text { Group } \\
\text { G }\end{array}$ \\
\hline GR & 3 & 4 & 6 & 6 & 6 & 6 & 6 \\
\hline GB & 7 & 7 & 5 & 6 & 7 & 6 & 7 \\
\hline Al & 5 & 5 & 5 & 5 & 5 & 5 & 5 \\
\hline L & 7 & 7 & 5 & 7 & 7 & 4 & 5 \\
\hline GDT & 7 & 6 & 5 & 7 & 8 & 6 & 4 \\
\hline GO & 7 & 7 & 4 & 7 & 6 & 6 & 7 \\
\hline Total & 36 & 36 & 30 & 38 & 39 & 33 & 34 \\
\hline
\end{tabular}


Figure 3. Some rich pictures of indicator use to emerge in the POINT workshops

A

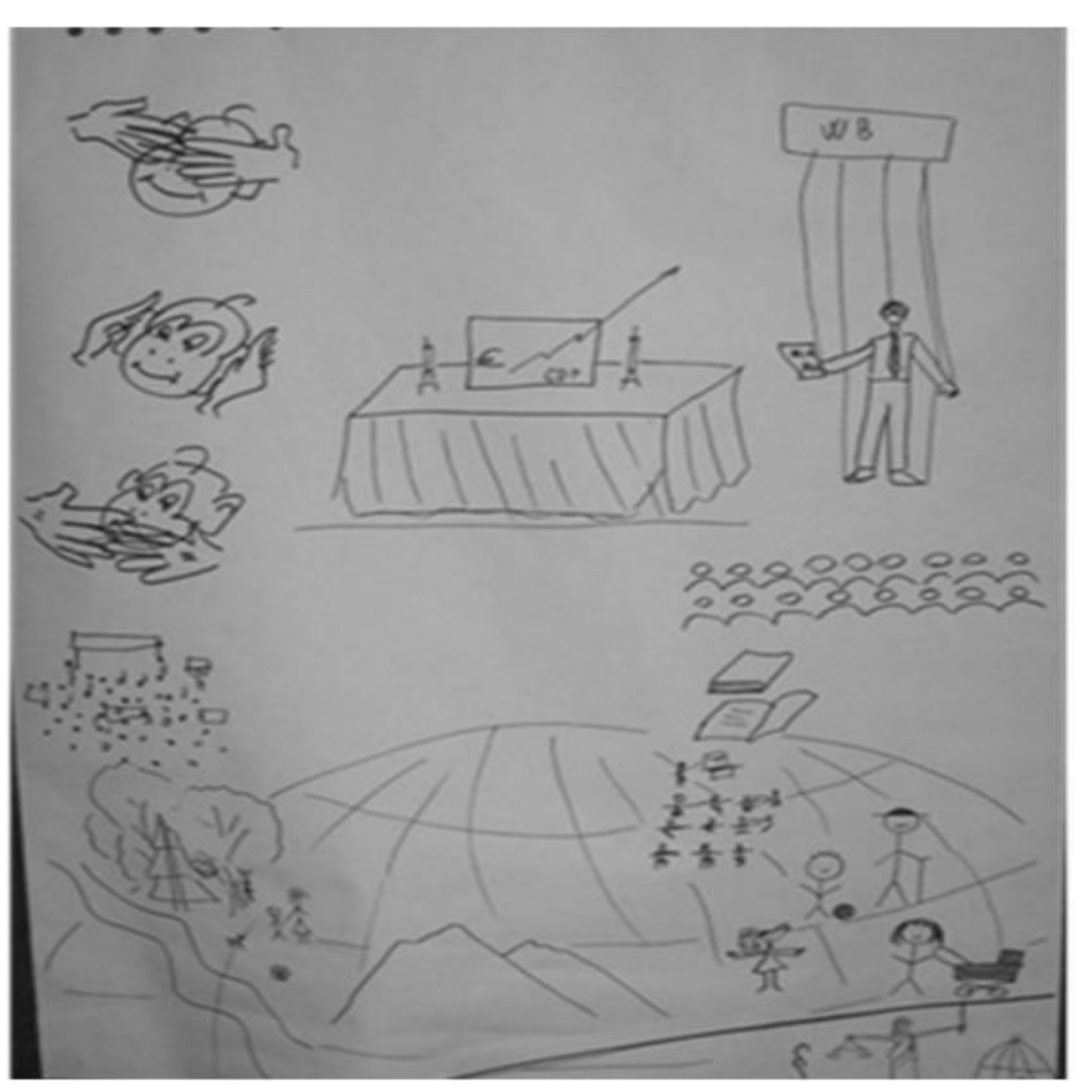

B

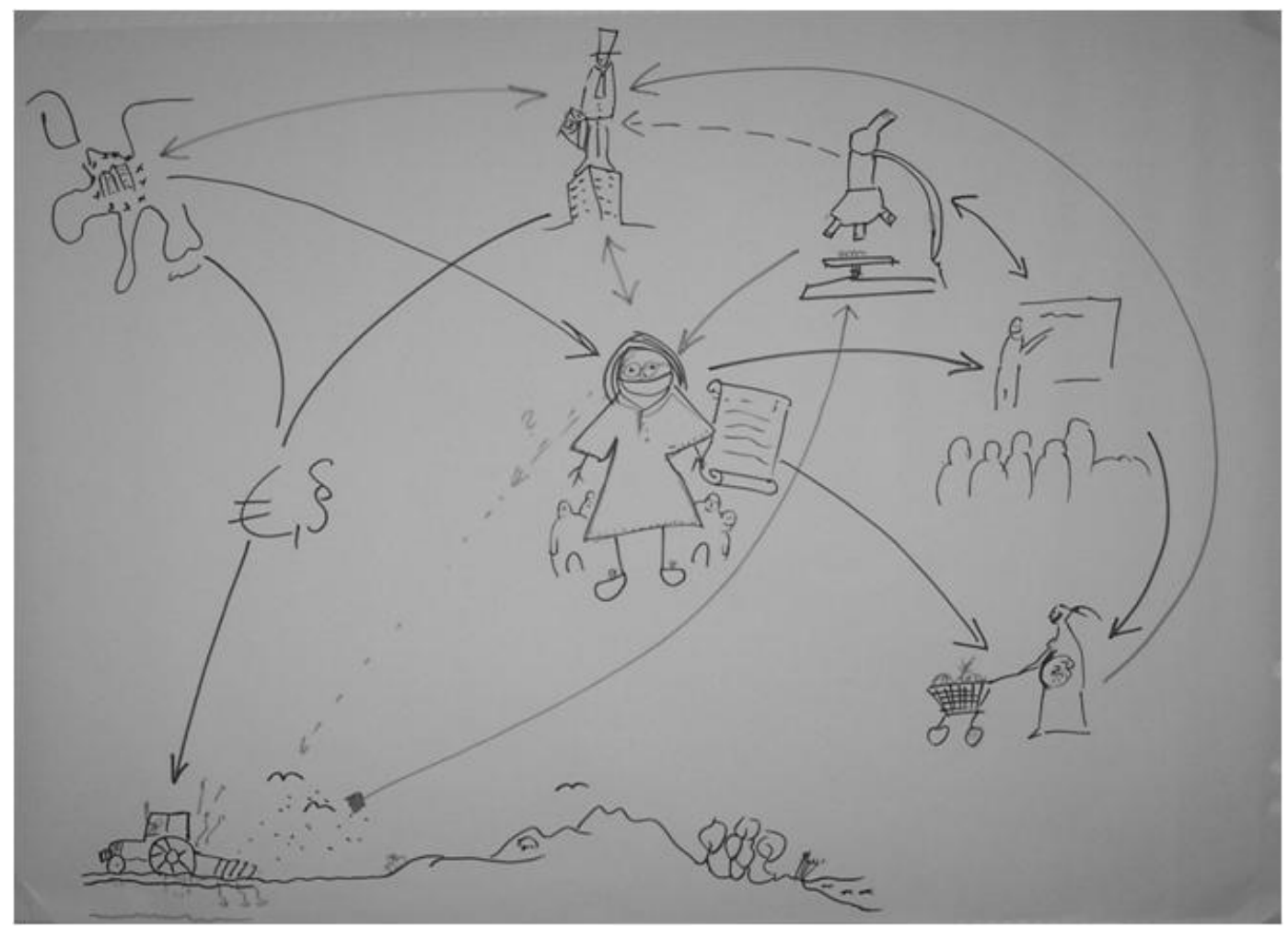



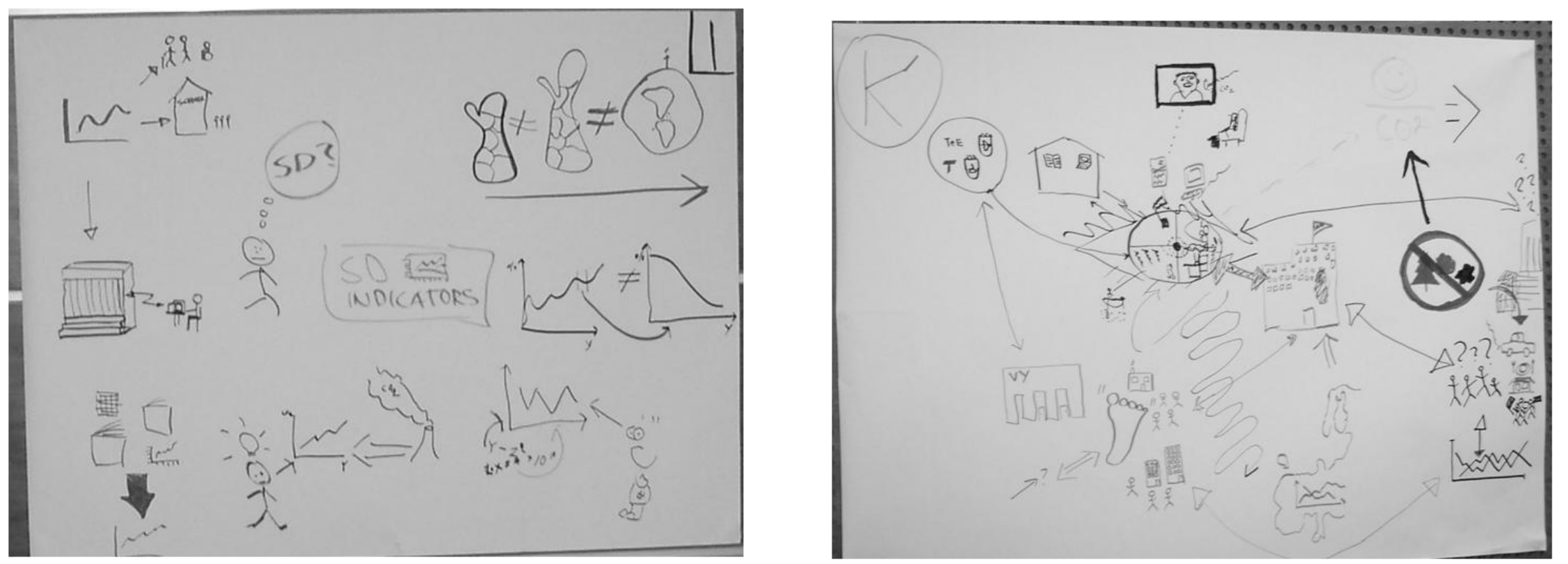

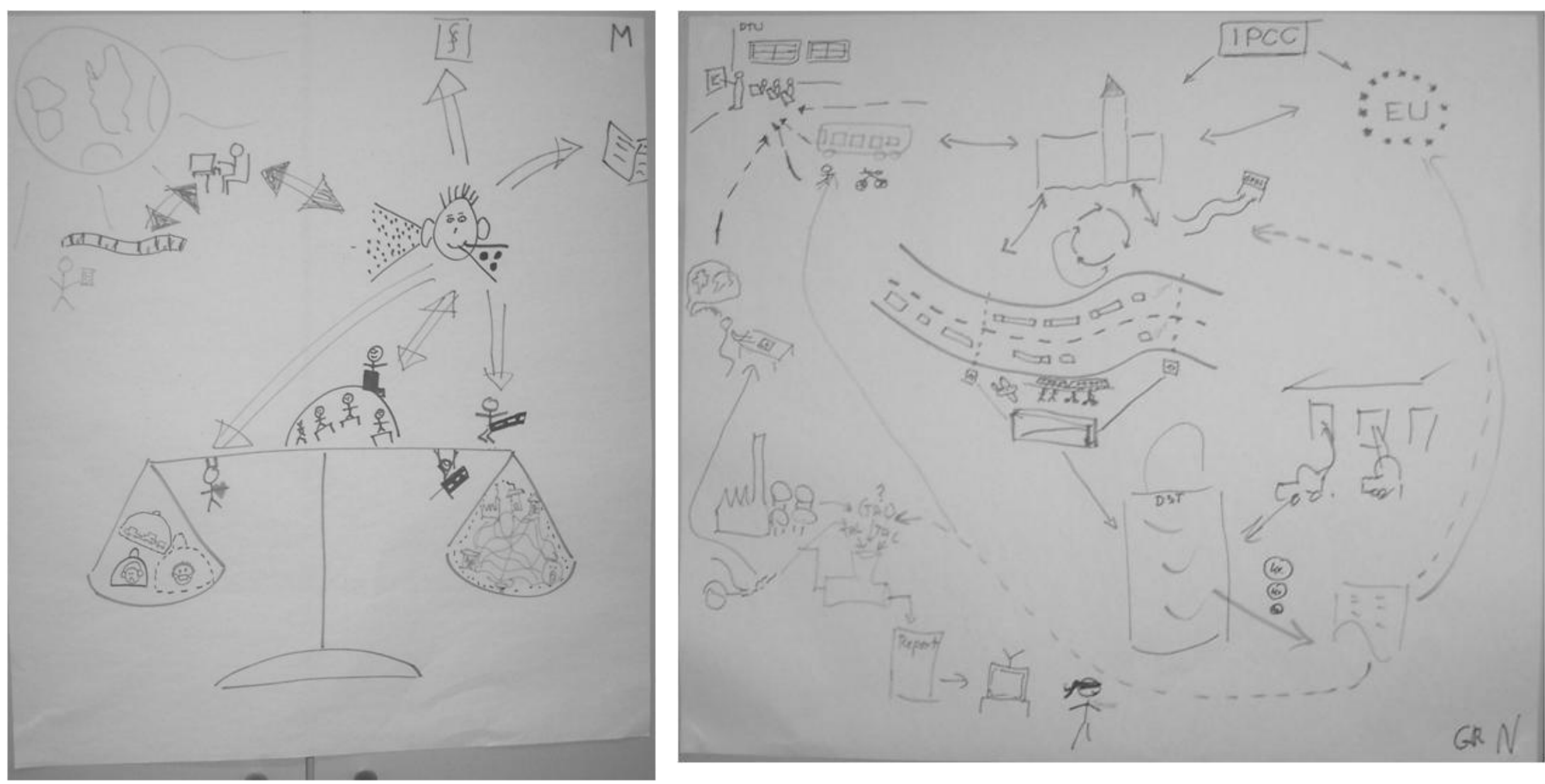


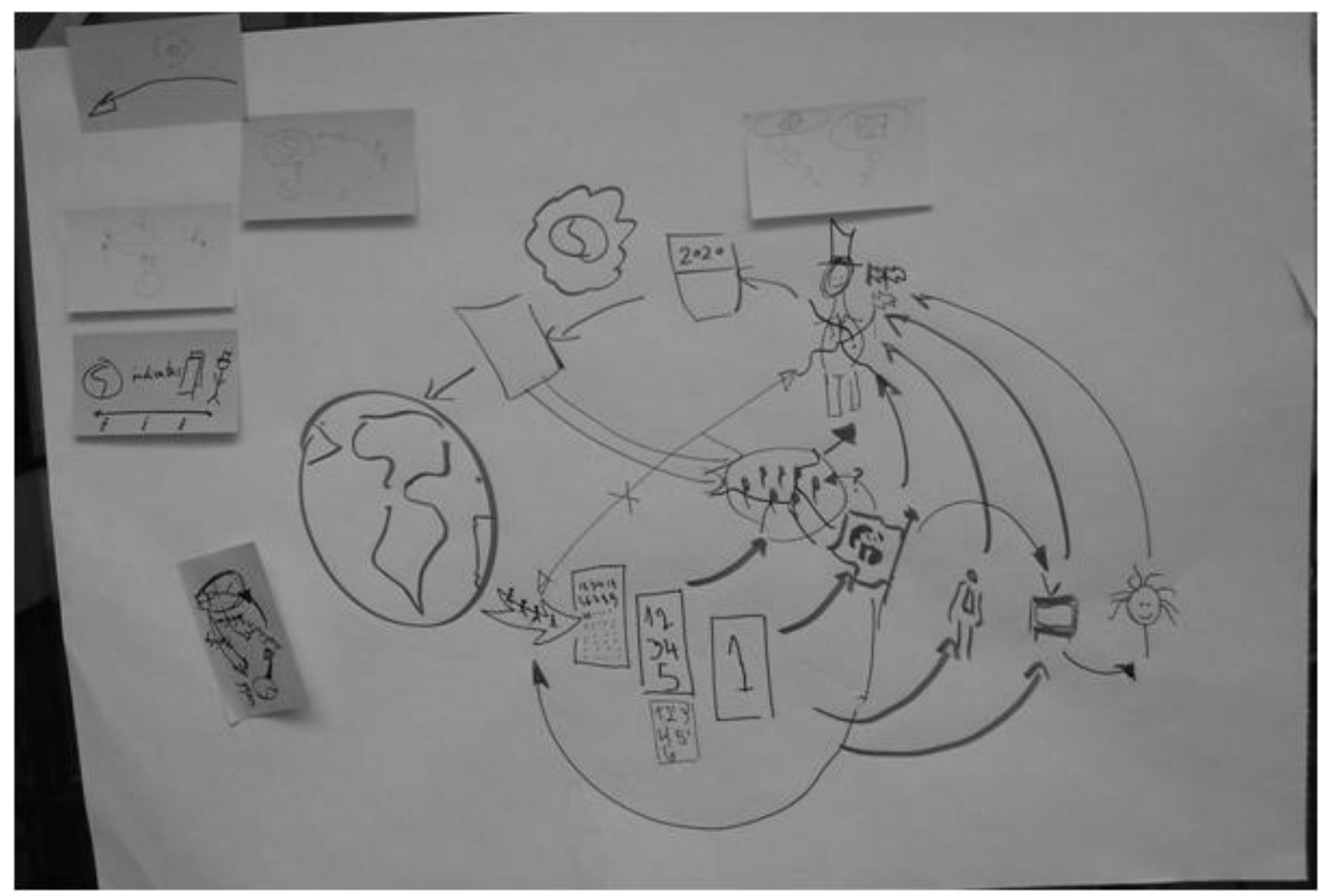

